\title{
Notas para o debate das relações de exploração-opressão na sociedade patriarcal-racista-capitalista
}

\section{Notes for the debate of the relationship between exploitation and oppression in a patriarchal-racist-capitalist society}

\section{Milena Fernandes Barroso ${ }^{a}$}

Resumo: O artigo problematiza a relação entre exploração e opressão a partir da perspectiva de que o capitalismo está fundamentalmente ligado ao patriarcado e ao racismo - não como legado, mas como necessidade. Destaca-se a importância de apreensão desses sistemas de forma consubstanciada para uma análise da totalidade, já que, nas relações sociais, essas contradições se fundam, como pode ser visto, na indissociabilidade entre as determinações de sexo/gênero, étnico-raciais e de classe.

Palavras-chave: Exploração-opressão. Patriarcado-racismo-capitalismo. Relações sociais.
Abstract: This article aims to discuss the relationship between exploitation and oppression, considering capitalism as a system fundamentally linked to patriarchy and racism - not as a legacy, but as a necessity. It is important to comprehend these systems in a substantiated way for an analysis of the totality, since these contradictions merge in the context of social relations, as can be seen in the indissolubility between determinations of sex/gender, ethnic-racial and class.

Keywords: Exploitation-oppression. Patriarchyracism-capitalism. Social relations.

\section{Introdução}

relação entre exploração e opressão está diretamente relacionada
à questão da relação estrutural entre patriarcado, racismo e capita-
lismo. Esse tema foi objeto de vários debates, na década de 1970,

aUniversidade Federal do Amazonas (Ufam), Instituto de Ciências Sociais, Educação e Zootecnia (ICSEZ), Parintins-AM, Brasil. 
entre teóricos e partidários do pensamento materialista e feminista-marxista (Arruzza, 2015). Neste sentido, questiona-se: seria o patriarcado e o racismo sistemas autônomos em relação ao capitalismo? Ou ainda: seria o capitalismo indiferente ao patriarcado e ao racismo? A partir dessas questões, problematiza-se neste artigo a importância de uma unidade dialética entre as relações sociais de sexo/gênero, étnico-raciais e de classe para a apreensão das contradições que constituem a realidade concreta.

Não é novidade que o modo de produção capitalista atinge ao máximo "a contradição presente em todas as formações econômico-sociais anteriores assentadas na apropriação privada dos meios de produção e dos produtos do trabalho humano" (Saffioti, 2013, p. 53). ${ }^{1}$ Esse modo de produção tem na acumulação o seu motor por meio da produção de mais-valor via exploração do trabalho e engendra relações sociais mediadas por mercadorias, em que as necessidades humanas são substituídas pela produção de "coisas" alheias a estas. A saturação empírica da mercadoria como categoria, "além de fazer-se acompanhar por uma divisão social do trabalho extremamente desenvolvida, marca o divórcio entre o valor de uso e o valor de troca dos produtos do trabalho" (Idem). Isso ocorre porque o valor de troca passa a presidir o processo social da produção, determinando, inclusive, a própria força de trabalho e resultando no ocultamento da exploração sob "uma aparência puramente econômica, coisificada e quantificada abstratamente, fazendo com que as taxas de exploração sejam travestidas de lucratividade" (Fontes, 2010, p. 22). ${ }^{2}$ Assim, é possível afirmar que a mercadoria não se

1. Marx (2013, p. 262) elucida esse processo ao apreender os pressupostos da relação capital-trabalho: “A relação-capital pressupõe a separação entre os trabalhadores e a propriedade das condições da realização do trabalho. Tão logo a produção capitalista se apoie sobre seus próprios pés, não apenas conserva aquela separação, mas a reproduz em escala sempre crescente. Portanto, o processo que cria a relação-capital não pode ser outra coisa que não o processo de separação de trabalhador da propriedade das condições de seu trabalho".

2. "Embora o lucro de cada movimento singular do capital decorra da exploração do trabalhador livre pelo proprietário (de meios de produção e/ou de recursos sociais de produção), a conversão de dinheiro em capital envolve toda a vida social numa complexa relação que repousa sobre a produção generalizada e caótica de trabalhadores cada vez mais 'livres', expropriados de todos os freios à sua subordinação mercantil. Somente em presença dessas condições sociais o processo produtor de mercadorias, no qual reside a extração do mais-valor, pode se realizar. É por obscurecer, por velar tal base social, que a produção capitalista, ou o 
refere a um objeto em si, mas é a forma pela qual os sujeitos estabelecem relações sociais no capitalismo.

Nessa direção, o capitalismo não é apenas um padrão de produção: trata-se de um amplo, complexo e expansivo processo histórico-social e político-econômico. Seria, portanto, necessariamente ligado ao racismo e ao sexismo (Federici, 2017) — não como legado, mas como necessidade própria do capitalismo, pois existe "não apenas uma relação simbiótica entre o trabalho assalariado contratual e a escravidão, mas também, e junto com ela, a dialética que existe entre acumulação e destruição da força de trabalho" - situação que as mulheres vivenciam de forma particular através da apropriação, opressão e exploração de seus corpos, seu trabalho e sua vida. Disso apreende-se a consubstancialidade entre patriarcado, racismo e capitalismo e, consequentemente, a indissociabilidade entre exploração e opressão. Essa imbricação, com frequência invisível, caracteriza o atual modelo societário ${ }^{3}$ e compõe uma nova realidade historicamente constituída.

\section{A indissociabilidade entre exploração e opressão}

O debate da relação entre exploração e opressão, apesar de profícuo, se tornou fora de moda num contexto em que as críticas ao capitalismo retrocederam e outras correntes do pensamento feminista se concretizaram (Arruzza, 2015). ${ }^{4}$ Ademais, mesmo com o risco de parecer "fora" de tempo, algumas teóricas feministas continuaram a trabalhar com essas questões a partir de motivações que se mantêm nos dias atuais, entre as quais a necessidade de explicar teoricamente as relações estruturais entre opressão e exploração. Contudo, esse tema ainda ocupa lugar secundário nos debates políticos e na produção teórica referenciada na teoria social crítica em geral. Prevalece,

\footnotetext{
momento da atividade produtiva de valorização do capital se apresenta como meramente 'econômico', apesar de envolver toda a existência social" (Fontes, 2010, p. 42).

3. Neste artigo, essa relação é considerada sempre quando se faz referência à sociedade capitalista.

4. Arruzza (2015) refere-se ao debate de gênero a partir de uma perspectiva liberal, da essencialização das relações entre homens e mulheres e da desistoricização do gênero.
} 
apesar de alguns deslocamentos importantes, a visão de que as classes sociais são homogêneas ou de que a exploração é em si mesma a única determinação das relações capitalistas. O questionamento a essas visões, por sua vez, parte da perspectiva de que "há expressões de hierarquias no interior da classe trabalhadora, advindas da própria forma de organização da sociedade" (Cisne, 2014 , p. 23). São quatro as principais teses que debatem o tema: a tese da indiferencialidade do capitalismo sobre as opressões (Wood, 2011); o ponto de vista da teoria unitária (Arruzza, 2015); a perspectiva da interseccionalidade (Crenshaw, 1989 e 2002) e a perspectiva da consubstancialidade e coextensividade das relações sociais (Kergoat, 2010; Saffioti, 2004; Cisne, 2014).

Wood (2011), que defende a tese da "indiferencialidade do capitalismo" sobre as opressões, considera a opressão de gênero como reminiscente de formações sociais e modos de produção prévios ao capitalismo, quando o patriarcado diretamente organizava e determinava uma estrita divisão sexual do trabalho. Para a autora, o capitalismo é, em si, indiferente às relações de gênero, ou seja, a igualdade racial ou de sexo/gênero não é antagônica ao capitalismo, pois o capitalismo é indiferente às identidades sociais das pessoas que explora e provavelmente cooptará quaisquer opressões que estejam cultural e historicamente disponíveis, em qualquer uma de suas definições — assim, a relação entre exploração e opressão é meramente instrumental e contingente. Conforme destaca a autora,

Embora o capitalismo possa usar e faça uso ideológico e econômico da opressão de gênero, essa opressão não tem um status privilegiado na estrutura do capitalismo. Ele poderia sobreviver à erradicação de todas as opressões específicas das mulheres, na condição de mulheres — embora não pudesse, por definição, sobreviver à erradicação da exploração de classe. Isso não quer dizer que o capitalismo tenha passado a considerar a liberação das mulheres necessária ou inevitável. Mas significa que não há necessidade estrutural específica de opressão de gênero no capitalismo, nem mesmo uma forte disposição sistêmica para ela. (Wood, 2011, p. 232)

Contrapondo Wood, Federici (2017, p. 11) assevera que a opressão das mulheres "na sociedade capitalista não é o legado de um mundo pré-moderno, 
mas sim uma formação do capitalismo, construída sobre diferenças sexuais existentes e reconstruída para cumprir novas funções sociais". Para Arruzza (2015), Wood empreende uma confusão entre a dimensão lógica e a dimensão histórica da análise das relações de classe. Ainda que se pudesse supor de um ponto de vista absolutamente abstrato que a exploração capitalista "não precisa" da opressão para sobreviver, todo o seu desenvolvimento histórico a evidencia como uma necessidade absolutamente imprescindível de sua formação social (Farris, 2015; Góes, 2015). Isso traz o debate sobre o que é funcional ao capitalismo e sobre o que, além de funcional, é uma consequência necessária dele.

Arruzza (2015), em direção distinta à tese de Wood, considera que o capitalismo produz opressão por necessidade e, assim, localiza o argumento tanto no nível estrutural lógico como no nível histórico. Isso, em parte, dialoga com a discussão estabelecida nos termos de Wood (2011), porém considera impresumível a cisão desses níveis da análise. Arruzza defende a "tese unitária", segundo a qual "nos países capitalistas não existe mais um sistema patriarcal que seja autônomo do capitalismo. Relações patriarcais continuam a existir, mas não são parte de um sistema separado" (Arruzza, 2015, p. 37). Para a autora, considerar que o patriarcado não é um sistema autônomo dentro do capitalismo não implica aferir que a opressão de gênero não exista; por outro lado, busca não reduzir "cada aspecto da opressão para simplificá-la a uma consequência mecânica ou direta do capitalismo, nem busca oferecer uma explicação baseada somente em termos econômicos" (Idem, p. 38).

Arruzza não subestima a centralidade da opressão de gênero, da mesma forma que não concorda com a ideia de que o patriarcado seria hoje um sistema autônomo, e insiste na necessidade de considerar o capitalismo não como um conjunto de leis puramente econômicas, mas antes como uma complexa e articulada ordem social que tem seu núcleo constituído de relações de exploração, dominação e alienação. Para a autora, o desafio que se coloca é entender como a dinâmica de acumulação de capital continua a produzir, reproduzir, transformar e renovar relações hierárquicas e opressivas, sem expressar esses mecanismos em termos estritamente econômicos ou automáticos.

O conceito de interseccionalidade, por sua vez, foi oficialmente sistematizado pela crítica e teórica estadunidense Kimberlé Crenshaw em 1989, 
a partir da sua inserção no movimento Black Feminism norte-americano, para analisar como raça, gênero e classe se interseccionam e geram diferentes formas de opressões. Para Crenshaw (2002, p. 177),

A interseccionalidade é uma conceituação do problema que busca capturar as consequências estruturais e dinâmicas da interação entre dois ou mais eixos da subordinação. Ela trata especificamente da forma pela qual o racismo, o patriarcalismo, a opressão de classe e outros sistemas discriminatórios criam desigualdades básicas que estruturam as posições relativas de mulheres, raças, etnias, classes e outras.

As controvérsias em torno da interseccionalidade dizem respeito à perspectiva "geométrica" e transdisciplinar de intersecção entre as opressões. Kergoat (2010, p. 98) destaca que se trata de uma tentativa de entender "a variedade das interações das relações de gênero e de 'raça', o mais próximo possível da realidade concreta das mulheres afro-americanas". A autora destaca o próprio título do artigo de Crenshaw, "Mapeamento das margens", para tecer sua crítica à perspectiva da autora: "pensar em termos de cartografia nos leva a naturalizar as categorias analíticas". Nessa mesma direção, destaca Elsa Dorlin (apud Kergoat, 2010, p. 98):

[...] a definição [de Crenshaw] das relações sociais como setores de intervenção implica que as mulheres [...] que enfrentam mais do que uma discriminação se acham em setores isolados. [...] O conceito de interseccionalidade e, de maneira geral, a ideia de intersecção, dificulta pensar uma relação de dominação móvel e historicamente determinada [...]. Em outros termos, a interseccionalidade é um instrumento de análise que coloca as relações em posições fixas, que divide as mobilizações em setores, exatamente da mesma maneira pela qual o discurso dominante naturaliza e enquadra os sujeitos em identidades previamente definidas.

As referidas críticas são pertinentes: a interseccionalidade, de fato, não consegue apreender a dinâmica complexa das relações sociais. Ademais, acreditamos que a interseccionalidade pode funcionar como um instrumento técnico-operativo aplicado às políticas públicas por possibilitar a conexão 
das desigualdades sociais num nível das práticas sociais — por intermédio da integração de marcadores sociais tais como sexo/gênero, classe, "raça", etnicidade, geração, deficiência e orientação sexual. Soma-se a isso o seu caráter político, uma vez que a interseccionalidade é também uma forma de luta contra as opressões e, portanto, um instrumento de luta política para o movimento de mulheres negras (Hirata, 2014; Marcondes et al., 2013). Contudo, não nos parece pertinente a fragmentação entre o nível da análise e o da intervenção.

A partir de um ponto de vista materialista, histórico e dinâmico, Kergoat (2010) defende a consubstancialidade e a coextensividade como uma lente ou possibilidade de apreender a relação entre exploração e opressão ou as relações sociais a partir de "unidade de substância". Ao que parece, sua discordância principal com Arruzza localiza-se na importância que atribui à diferenciação analítica ou autonomia relativa dos tipos de relações sociais, “operação por vezes necessária à sociologia, mas que é analítica e não pode ser aplicada inadvertidamente à análise das práticas sociais concretas" (Kergoat, 2010, p. 93). Dessa análise é possível apreender as relações patriarcais, mesmo que elas não funcionem sozinhas. São práticas que não se permitem apreender por noções geométricas como adição, intersecção e multiposicionalidade, uma vez que são móveis, ambíguas e ambivalentes. Assim, o ponto de vista de Kergoat (2010), também defendido por Saffioti (1987 e 2004), Silva (1992) e Cisne (2014), ${ }^{5}$ é que as relações sociais são consubstanciais; “[...] elas formam um nó que não pode ser desatado no nível das práticas sociais, mas apenas na perspectiva da análise sociológica; e as relações sociais são coextensivas: ao se desenvolverem, as relações sociais de classe, gênero e 'raça' se reproduzem e se coproduzem mutuamente" (Kergoat, 2010, p. 94). Ou seja, patriarcado e capitalismo - mesmo que tenham particularidades que permitam uma caracterização em si -, nessa perspectiva, compõem um sistema dependente um do outro a partir do pressuposto de que tais relações são dinâmicas e que existem três relações

5. Angela Davis, mesmo que não faça alusão à consubstancialidade, realiza uma análise a partir da simbiose entre as contradições centrais das relações sociais (patriarcado, racismo e capitalismo) em suas obras, com destaque para o seu clássico trabalho Mulheres, raça e classe, de 1981. 
sociais fundamentais que se imbricam e são coextensivas: sexo/gênero, a classe e a "raça" (Kergoat, 2010). ${ }^{6}$

Porém essa perspectiva apresenta-se sob prismas distintos. Cisne (2014, p. 30-31) alude à consubstancialidade entre opressão-exploração, mas defende a primazia ontológica da exploração sobre a opressão ou a centralidade da classe em relação ao sexo/gênero e raça (Cisne, 2014). Apesar de destacar a importância de não secundarizar os demais elementos estruturadores das relações sociais, destaca a centralidade da classe em razão do fundamento do modo de produção capitalista, que particulariza e caracteriza a formação social atual (ou seja, considera que, em última instância, as relações econômicas são definidoras). Para a autora, não se trata de hierarquizar exploração e opressão, mas de conferir à classe uma prioridade ontológica ao considerar que apenas a classe possibilita a articulação das demais contradições. Para Saffioti (1987) e Silva (1992), a determinação “em última instância” do econômico subordina as relações de sexo/gênero às relações de produção, afinal, "o conceito de relações de gênero não goza do mesmo estatuto teórico que o conceito de relações entre as classes sociais" (Silva, 1992, p. 21). Kergoat (2010, p. 99), por sua vez, considera que colocar o problema nos termos da consubstancialidade das relações sociais permite uma outra abordagem:

[...] de acordo com uma configuração dada de relações sociais, o gênero (ou a classe, a raça) será - ou não será — unificador. Mas ele não é em si fonte de antagonismo ou solidariedade. Nenhuma relação social é primordial ou tem prioridade sobre outra. Ou seja, não há contradições principais e contradições secundárias. Quando as mulheres da rede hoteleira Accor enfrentam conflitos, o fazem como mulheres, trabalhadoras, mulheres negras; não fazem reivindicações separadas. Lutando dessa maneira, elas combatem a superexploração de todos e todas, e sua luta, assim, tem alcance universal.

6. A perspectiva da consubstancialidade foi elaborada por Danièle Kergoat inicialmente em termos de articulação entre sexo e classe social, e, posteriormente, em termos de imbricação entre classe, sexo e "raça". Saffioti também parte inicialmente das relações de gênero e classe e, posteriormente, no livro $O$ poder do macho, publicado em 1987, amplia a percepção da simbiose acrescentando a categoria raça/etnia. 
Assim, as relações sociais podem incluir uma ou mais dimensões em termos de determinantes, ${ }^{7}$ mas na realidade concreta se encontram imbicadas, "podendo ser encontradas várias combinações, inclusive contraditórias, sob o ponto de vista de uma análise monolítica que considere a autonomia relativa de um dos sistemas de dominação-exploração" (Silva, 1992, p. 26). Para essa abordagem, não há primazia entre as relações: elas nem são simplesmente superpostas ou adicionadas, nem intersecções - são imbricadas, consubstanciais e conformadas. O horizonte teórico-político desse uso é a transformação da sociedade, das relações capitalistas, que também são relações hierárquicas de sexo/gênero e "raça". ${ }^{8}$

Nessa direção, feministas materialistas como Guillaumin, ainda em 1972, pautava a construção social do que se entende por "raça", considerando-a "um processo de naturalização baseado num sistema de marcas físicas totalmente arbitrárias que teve a sua origem e causa no sistema escravista do século XVIII" (Cisne e Gurgel, 2014, p. 249). E demonstrou que tanto as opressões de sexo como as de raça se apoiam num processo semelhante de naturalização de determinados grupos sociais. Contudo, o escravismo não pode ser visto de forma isolada, mas como origem da acumulação capitalista nas Américas, imposto pela Europa a povos e países que não haviam experimentado o feudalismo.

Além disso, a despeito de ter origem com a escravidão moderna, também não pode ser considerado apenas a herança cultural escravista. Afinal, "a ciência do século XX derrubou por completo qualquer pretensão à cientificidade do argumento racialista da hierarquia entre raças" e, não obstante, o "racismo continuou e continua a orientar formas opressivas de exercício do poder e a interpenetrar-se nas relações de produção, criando hierarquias de funções" (Mattos, 2017). Logo, o "racismo não é apenas um problema ético, uma categoria jurídica ou um dado psicológico. Racismo é uma relação social, que se estrutura política e economicamente" (Almeida,

7. Por exemplo, podem-se identificar relações de opressão-exploração do rico sobre o pobre, do homem sobre a mulher, do branco sobre o negro, e do heterossexual sobre o homossexual ou o bissexual (Silva, 1992).

8. Cabe elucidar que uso do termo "raça" é político e justifica-se como uma categoria social de dominação e de exclusão. 
2016, p. 23), podendo ser facilmente apreendida no constrangimento e nas inúmeras violências vivenciadas pelas mulheres negras, por exemplo. A imbricação entre patriarcado, racismo e capitalismo revela, assim, hierarquias e privilégios nas relações sociais de sexo/gênero, étnico-raciais e classe. Nessa direção, Collins (apud Marcondes et al., 2013, p. 137) destaca que "todas as mulheres negras compartilham a comum experiência de comporem uma sociedade que as desprivilegiam" e "a forma como os estereótipos vinculados à representação social são fontes inesgotáveis de violência contra as mulheres negras e também confinadores sociais". Reconhecer essas hierarquias implica reter que mulheres pobres, negras e indígenas sofrem mais intensamente as opressões da ordem patriarcal, pois carregam no corpo as marcas da opressão-exploração do sexismo, do racismo e do classismo.

Ademais, constatar que as opressões persistem historicamente e estão fundidas necessariamente à exploração é uma possibilidade para a unificação das lutas por emancipação política e humana, diga-se, a partir de uma totalidade diversificada, que reconheça as múltiplas experiências objetivas e subjetivas de sexo/gênero (incluindo as sexualidades) e étnico-raciais. É um esforço teórico-político enfrentar os antagonismos existentes na sociedade, que respondam a situações de dominação-exploração em que se encontram as mulheres, as minorias étnicas e os pobres (Saffioti, 1987; Silva, 1992). A finalidade é, portanto, “desnaturalizar radicalmente as construções que se baseiam na diferenciação das desigualdades, sem com isso perder de vista a dimensão concreta das relações sociais" (Kergoat, 2010, p. 99). Essa análise discorda, por exemplo, das abordagens que consideram que as relações de classe se inscrevem unicamente na instância econômica, e as relações patriarcais, unicamente na instância ideológica. Parte-se da compreensão de que "cada um desses sistemas possui suas próprias instâncias, que exploram economicamente, dominam e oprimem", mas que "articulam-se entre si, de maneira intra e intersistêmica" (Idem).

Não obstante, se a teoria social crítica objetiva a apreensão da totalidade e isso implica, pois, considerar o capitalismo como totalidade histórica, dinâmica e contraditória e assim realizar análises e construir estratégias que tenham em conta as complexas relações no interior dessa totalidade (Mattos, 
2017), pode-se aferir que as relações de opressão/dominação patriarcal estão imbricadas às relações de exploração necessariamente, e não contingencialmente, em concordância com Arruzza (2015). Logo, entende-se que o patriarcado não se limita ao campo da dominação, modelado pela ideologia machista, tampouco é um fenômeno reduzível a relações interpessoais. Diferentemente, possui um caráter e consistência societal (Arruzza, 2015) e é também um sistema de exploração, ou melhor, ele possui uma dupla dimensão: a dominação (opressão) e a exploração ${ }^{9}$

Portanto, não há dúvidas sobre o fato de que as opressões decorrentes do patriarcado antecedem o capitalismo. A questão aqui empreendida é a do reconhecimento de que essas opressões sobreviveram à sua emergência e tornaram-se necessárias às relações sociais capitalistas. ${ }^{10}$ Saffioti (2004) argumenta que a dominação patriarcal na cena contemporânea não é a mesma da Atenas clássica ou da Roma antiga. A autora refere-se a uma "máquina do patriarcado" para demonstrar a força e a abrangência dessa dominação-opressão que se trata de uma estrutura forte e sólida que pode ser acionada por qualquer um, inclusive por mulheres.

Contudo, apesar de reformulado conceitualmente e de suas manifestações atualizadas conforme o movimento da realidade e os avanços no

9. Não se trata aqui de uma analogia à perspectiva weberiana do patriarcado, como "um tipo de dominação em que o senhor é a lei e cujo domínio está referido ao espaço das comunidades domésticas ou formas sociais mais simples, tendo sua legitimidade garantida pela tradição" (Castro e Lavinas, 1992, p. 237). O conceito weberiano de patriarcado, além de inapropriado às formas capitalistas por se tratar de um conceito específico do contexto social no qual teve sua origem (no caso, anterior ao advento do Estado), é considerado uma interpretação patriarcal do patriarcado. Nessa perspectiva, Pateman (1993, p. 49) assinala que "A interpretação patriarcal do patriarcado como direito paterno provocou, paradoxalmente, o ocultamento da origem da família na relação entre marido e esposa. O fato de que os homens e mulheres fazem parte de um contrato de casamento - um contrato original que instituiu o casamento e a família - e de que eles são maridos e esposas antes de serem pais e mães é esquecido".

10. Conforme destaca Mattos (2017, p. 1), "[e]m modos de produção anteriores ao capitalismo, especialmente nas relações de produção baseadas na unidade familiar, voltadas prioritariamente para a subsistência, a subordinação da mulher (e das crianças) ao poder patriarcal organizava em grande medida o processo produtivo. A acumulação primitiva de capital, um processo de expropriação que marcou a separação dos agora proletários e proletárias dos meios de produção necessários a suprir sua subsistência lançando-os ao mercado, consistiu, em grande medida, na quebra dessas relações de produção organizadas nas unidades familiares. No entanto, o patriarcado sobreviveu, transformado e incorporado pelo capitalismo". 
campo dos direitos das mulheres, é importante dizer que a base material do patriarcado não foi destruída. Se na Roma antiga o patriarca tinha direito de vida e morte sobre sua mulher, hoje o feminicídio ou a morte de mulheres por motivos sexistas é comumente justificada pelo desvio em torno das expectativas de condutas e caminha na direção da culpabilização das vítimas. Além disso, sobrevive e combina-se à valorização do modelo familiar monogâmico como norma e na afirmação de padrões heteronormativos. Assim, compreende-se o capitalismo também como sistema de dominação masculina de opressão e exploração das mulheres, o qual se mantém sob uma base material concreta e ancora-se numa economia doméstica e na violência sexista, que garante a produção e a reprodução da vida.

De forma contrária à comum dicotomia entre patriarcado e a classe, o esforço aqui é o de empreender um conteúdo histórico particular ao patriarcado, ${ }^{11}$ o qual implica a legitimação e a organização das relações sociais capitalistas que subalternizam duplamente o trabalho (e a posição social em geral) da mulher, seja pela apropriação do trabalho reprodutivo - o capital destruiu as relações de produção baseadas na unidade familiar, mas não dispensou a família como unidade primordial na execução de uma série das formas de trabalho essenciais para a reprodução da força de trabalho - , que rebaixa o custo da força de trabalho em geral, permitindo ao capital remunerá-la com um salário inferior (ou não salário) ${ }^{12}$ ao que seria necessário à sua reprodução caso todas essas condições essenciais à sobrevivência fossem compradas no mercado (Mattos, 2017), conferindo aos homens o poder do salário, seja pela incorporação da mulher ao mercado de trabalho assalariado em posições

11. Saffioti (2004) enumera seis justificativas para a manutenção do patriarcado como categoria útil para demonstrar a dominação-exploração das mulheres: 1) não se trata de uma relação privada, mas civil; 2) dá direitos sexuais aos homens sobre as mulheres, praticamente sem restrição; 3) configura um tipo hierárquico de relação, que invade todos os espaços da sociedade; 4) tem uma base material; 5) corporifica-se; 6) representa uma estrutura de poder baseada tanto na ideologia quanto na violência. Para a referida autora, isso implica reconhecer que as mulheres ainda são objetos da satisfação sexual dos homens, reprodutoras de herdeiros, de força de trabalho e de novas reprodutoras. Essa "soma/mescla de dominação e exploração é entendida como opressão" (Saffioti, 2004, p. 105).

12. Aqui, refere-se ao trabalho doméstico não remunerado realizado prioritariamente pelas mulheres. 
subalternas ou com remunerações mais baixas. ${ }^{13}$ Diga-se, incorporação imprescindível. Afinal, o trabalho doméstico não remunerado continuou a desempenhar um papel central na organização capitalista do trabalho e é "um dos principais pilares da produção capitalista, ao ser o trabalho que produz a força de trabalho" (Federici, 2017, p. 12). Nessa perspectiva, acredita-se que a dominação masculina é resultado também do poder que o salário confere aos homens, e não apenas da natureza "improdutiva" do trabalho doméstico.

Disso pode-se aferir que não há separação entre a exploração capitalista e a opressão patriarcal e racista, mas uma imbricação entre esses sistemas — ou, como expõe Saffioti (1984, p. 19), “opressão e exploração não são propriamente fenômenos distintos", apenas se manifestam como dimensões específicas (política, cultural, social, sexual etc.) de um mesmo processo multidimensional. ${ }^{14}$ Exclusivamente para fins analíticos, torna-se possível distinguir entre o aspecto da opressão e o aspecto da exploração das mulheres, em que a opressão se manifesta nas relações de dominação (ideológicas), enquanto a exploração está mais diretamente ligada à dimensão econômica.

Defende-se a unidade dialética entre opressão e exploração na medida em que a opressão é veículo/motor para a exploração. Em outras palavras, através da opressão/dominação naturalizam-se relações, comportamentos, mentalidades, que se convertem em privilégios e desigualdades, os quais favorecem a exploração. Tais privilégios e desigualdades não se limitam ao sexo, mas abarcam as relações étnico-raciais. Assim, considera-se que "a opressão constitui, ao mesmo tempo, o veículo e o disfarce da exploração" e, apesar de afetar a todos (por seu caráter estruturante), incide de modos diferentes e com intensidades diversas sobre os elementos que pertencem a

13. Dados do Instituto Brasileiro de Geografia e Estatística (IBGE) confirmam essa tendência ao apontar que a renda média nacional do brasileiro é de $\mathrm{R} \$ 2.043$, sendo que os homens ganham, em média, $\mathrm{R} \$ 2.251$, e as mulheres, R\$ 1.762 (diferença de R\$ 489). Disponível em: <https://g1.globo.com/economia/ concursos-e-emprego/noticia/mulheres-ganham-menos-do-que-os-homens-em-todos-os-cargos-diz-pesquisa. ghtml>. Acesso em: 10 jan. 2018.

14. Saffioti tem como pressuposto para tal análise a relação também simbiótica entre produção e reprodução. Para a autora, produção e reprodução são faces de um mesmo sistema produtivo, "posto que qualquer modo de produção necessita da produção de meios de subsistência e da reprodução de seres humanos" (Saffioti, 1988, p. 143). 
uma e a outra categoria de sexo e raça (Saffioti, 1984, p. 24). Tais relações, apesar de suas particularidades, não atuam/funcionam de forma autônoma. Nos termos de Saffioti (2004, p. 215),

O importante é analisar estas contradições na condição de fundidas e enoveladas ou enlaçadas em um nó. [...] Não que cada uma destas condições atue livre e isoladamente. No nó, elas passam a apresentar uma dinâmica especial, própria do nó. Ou seja, a dinâmica de cada uma condiciona-se à nova realidade. De acordo com as circunstâncias históricas, cada uma das contradições integrantes do nó adquire relevos distintos. E esta motilidade é importante reter, a fim de não se tomar nada como fixo, aí inclusa a organização social destas subestruturas na estrutura global, ou seja, destas contradições no seio da nova realidade novelo patriarcado-racismo-capitalismo - historicamente constituída.

Isso faz reconhecer, por exemplo, que os homens retiram um benefício relativo da opressão de sexo/gênero e que as mulheres não experimentam dessa opressão de forma homogênea, embora estejam submetidas em seu conjunto ao poder opressivo do patriarcado. Da mesma forma, desigualdades de classe e étnico-raciais geram distintas formas de subjetividade, como já se destacou. Portanto, as relações sociais de sexo/gênero interatuam com as de classe e raça, operando na determinação das formas específicas - e hierarquizadas — de como as opressões são vividas objetiva e subjetivamente.

\section{Considerações finais}

Ao apreender a sociedade patriarcal-racista-capitalista, uma ordem que tem seu núcleo constituído de relações de exploração-opressão de sexo/ gênero, raça/etnia e classe, afora demonstrar a articulação necessária entre exploração-opressão, pretende-se contribuir para uma prática política de unidade. Logo, entende-se que separar a exploração das opressões — ou negar a centralidade das opressões ou as determinações para além da classe — pode cooperar para, além de fragmentar a apreensão da totalidade, segmentar as lutas. O patriarcado, com materialidade e cultura, penetrou em todas as esferas da vida social; o capitalismo mercantilizou todas as relações sociais; e, 
finalmente, o racismo, pela estrutura de poder, preconceito e discriminação, se espraiou em todo o corpo social como herança do escravismo. Assim, a suplantação da “opressão é impossível sob a lógica do capital, que a integrou de forma complexa e não linear à exploração do trabalho, sendo, portanto, indissociável da emancipação da totalidade da classe trabalhadora" (Mattos, 2017 , p. 2) — ou seja, uma sociedade emancipada só é possível se superadas as relações de opressões que a forjam. Desse ponto de vista, nenhuma forma de opressão pode ser entendida ou superada isoladamente, e a luta contra a opressão-exploração deve contemplar e incluir todas as camadas de oprimidos (Moraes, 2015).

Dito isso, acredita-se que afirmar o significado sócio-histórico das relações de raça e sexo/gênero também como contradições centrais na reprodução do modo de produção capitalista não significa, em absoluto, negar ou secundarizar a condição determinativa do papel da classe. Ao contrário, refere-se à necessidade de conferir substância material aos modos de ser e reproduzir da própria determinação de classe. Disso decorre que, ao apreendermos como se materializam as relações sociais de produção e reprodução no capitalismo, estamos levando em conta os processos concretos de que se vale a existência dessa forma social, de onde entendemos serem imprescindíveis as determinações de sexo/gênero e de raça, articulando, na perspectiva de totalidade, as determinações de classe.

Convém apreender esse processo não a partir de uma hierarquia de valores, mas de uma unidade dialética ou "unidade de substância" (Kergoat, 2010) entre as relações de sexo/gênero, raça e classe. A unidade pressupõe que nenhuma dessas relações tem primazia sobre a outra - afinal, é a complexa dinâmica dessa relação que expressa, por exemplo, a impossibilidade de se prescindir ou hierarquizar uma ou outra contradição no próprio processo de reprodução do capital ou sem as quais este não poderia se materializar. Ademais, é um dos pontos de partida para um feminismo materialista-histórico no qual a reprodução social ocupa um lugar indispensável.

Recebido em 19/1/18 - Aprovado em 20/6/18 


\section{Referências bibliográficas}

ALMEIDA, Sílvio Luiz de. Dossiê: marxismo e questão racial. Margem Esquerda, São Paulo, n. 27, $2^{\circ}$ sem. 2016.

ARRUZZA, Cinzia. Considerações sobre gênero: reabrindo o debate sobre patriarcado e/ou capitalismo. Outubro Revista, n. 23, p. 33-58, 2015. Disponível em: <http://bit. ly/1IV8ss1>. Acesso em: 30 out. 2017.

CASTRO, Mary Garcia; LAVINAS, Lena. Do feminino ao gênero: a construção de um objeto. In: COSTA, Albertina O.; BRUSCHINI, Cristina (Orgs.). Uma questão de gênero. Rio de Janeiro: Rosa dos Tempos, 1992. p. 216-251.

CISNE, Mirla. Feminismo e consciência de classe no Brasil. São Paulo: Cortez, 2014.

CISNE, Mirla; GURGEL, Telma. Os atuais desafios para o feminismo materialista: entrevista com Jules Falquet. Temporalis, Brasília, ano 14, n. 27, p. 245-261, jan./ jun. 2014. Disponível em: <http://portaldepublicacoes.ufes.br/temporalis/article/ viewFile/7984/5851>. Acesso em: 18 jan. 2018.

CRENSHAW, Kimberlé W. Demarginalizing the intersection of race and sex: a black feminist critique of discrimination doctrine, feminist theory and antiracist politics. Chicago: University of Chicago Legal Forum, 1989.

. Documento para o encontro de especialistas em aspectos da discriminação racial relativos ao gênero. Estudos Feministas, Florianópolis, v. 10, n. 1, p. 171-188, jan. 2002. DAVIS, Angela. Mulheres, raça e classe. São Paulo: Boitempo, 2016.

FARRIS, Sara. The Intersectional Conundrum and the Nation-State. Viewpoint Magazine, maio 2015. Disponível em: <http://bit.ly/1DbJbn4>. Acesso em: 15 maio 2015.

FEDERICI, Silvia. Calibã e a bruxa: mulheres, corpo e acumulação primitiva. São Paulo: Elefante, 2017.

FONTES, Virgínia. O Brasil e o capital-imperialismo: teoria e história. Rio de Janeiro: ESPJV/UFRJ, 2010.

GÓES, Camila; MUSSI, Daniela. A opressão de gênero e a imprescindível renovação do marxismo. Blog Junho, 15 jul. 2015. Disponível em: < http://blogjunho.com.br/a-opressaode-genero-e-a-imprescindivel-renovacao-do-marxismo>. Acesso em: 15 maio 2017.

HIRATA, Helena. Gênero, classe e raça: interseccionalidade e consubstancialidade das relações sociais. Tempo Social, São Paulo, v. 26, n. 1, 2014. Disponível em: <https:// www.revistas.usp.br/ts/article/view/84979>. Acesso em: 30 out. 2017. 
KERGOAT, Danièle. Dinâmica e consubstancialidade das relações sociais. Novos Estudos Cebrap, São Paulo, n. 86, mar. 2010. Disponível em: <http://www.scielo.br/ pdf/nec/n86/n86a05.pdf>. Acesso em: 15 out. 2017.

MARCONDES, Mariana M. et al. (Orgs.). Dossiê mulheres negras: retrato das condições de vida das mulheres negras no Brasil. Ipea, 2013. Disponível em: $<$ http://ipea.gov.br/portal/images/stories/PDFs/livros/livros/livro_dossie_mulheres_negras.pdf $>$. Acesso em: 18 jan. 2018. MARX, Karl. O capital: crítica da economia política. Livro I. São Paulo: Boitempo, 2013 (original de 1867).

MATTOS, Marcelo Bardaró. Ainda o sujeito histórico ou outros sujeitos? Notas introdutórias para o debate da esquerda socialista no Brasil. Blog Junho, 15 abr. 2017. Disponível em: $<$ http://blogjunho.com.br/ainda-o-sujeito-historico-ou-outros-sujeitos-notas-introdutorias-para-o-debate-da-esquerda-socialista-no-brasil>. Acesso em: 30 out. 2017.

MORAES, Maria Lygia Quartim de. Pós-modernismo, marxismo e feminismo. Blog da Boitempo, 2015. Disponível em: <https://blogdaboitempo.com.br/2015/03/05/posmodernismo-marxismo-e-feminismo>. Acesso em: $10 \mathrm{dez} .2017$.

PATEMAN, Carole. O contrato sexual. Paz e Terra: Rio de Janeiro, 1993.

SAFFIOTI, Heleieth. Mulher brasileira: opressão e exploração. Rio de Janeiro: Achiamé, 1984.

. O poder do macho. São Paulo: Moderna, 1987.

SAFFIOTI, Heleieth. Movimentos sociais: face feminina. In: CARVALHO, N. (Org.). A condição feminina. São Paulo: Vértice, 1988.

. Gênero, patriarcado, violência. São Paulo: Perseu Abramo, 2004.

. A mulher na sociedade de classes. São Paulo: Expressão Popular, 2013.

SILVA, Marlise Vinagre. Violência contra a mulher: quem mete a colher? São Paulo: Cortez, 1992.

WOOD, Ellen Meisins. Democracia contra capitalismo: a renovação do materialismo histórico. São Paulo: Boitempo, 2011.

\section{Nota da autora}

Milena Fernandes Barroso - Professora adjunta da Universidade Federal do Amazonas (Ufam), doutora em Serviço Social pela Universidade do Estado do Rio de Janeiro (UERJ).E-mail: mibarroso@yahoo.com.br 